\title{
Mentoria é uma arte, não um ofício
}

\author{
Mentoring is an art, not a trade
}

Luciana de Almeida Silva Teixeira' (1) | luciana.teixeira@uftm.edu.br

\section{RESUMO}

Introdução: Programas de mentoria têm se mostrado estratégias para o aprimoramento da formação dos futuros médicos, com alcance em aspectos pouco contemplados nos currículos formais. Este relato discute a experiência docente do exercício da mentoria para uma turma de graduação em Medicina, durante o período de seis anos (de 2014 a 2020).

Relato de experiência: As ações da mentoria foram planejadas semestralmente, em reuniões entre mentor e mentorados. As temáticas elegíveis foram escolhidas por meio de tempestade de ideias para convergir nas principais demandas coletivas. Abordaram-se os seguintes assuntos: visão do paciente ante a interação com estudantes das profissões da saúde, futuro dos médicos recém-formados, matriz de competências essenciais para a formação do médico, entre outros. Utilizaram-se mais frequentemente as seguintes ferramentas: rodas de conversa, atividades baseadas em metodologias ativas em pequenos e grandes grupos, encontros informais com a turma, encontros individuais, e espaços formais e informais de tecnologia da informação. As ações foram realizadas, ao longo dos seis anos, pelo mesmo docente, o que permitiu a construção e consolidação do vínculo entre mentor e mentorados.

Discussão: Assim, a mentoria se configurou como uma potente estratégia, conduzida com flexibilidade para permear as necessidades dos educandos, direcionando-as para o desenvolvimento individual e coletivo de profissionalismo. Entre os ganhos paralelos, destaca-se o estímulo ao desenvolvimento docente, condição que exigiu receptividade à interação e reconhecimento dos saberes dos aprendizes.

Conclusão: Por meio desta experiência, foi possível compreender que a essência da mentoria está relacionada ao vínculo e ao preparo de seres humanos para lidar com seres humanos, independentemente do papel social que estejam ocupando.

Palavras-chave: Mentoria; Medicina; Desenvolvimento Docente.

\begin{abstract}
Introduction: Mentoring programs have been strategies for improving the training of future doctors, covering aspects rarely contemplated in formal curriculum. This report discusses the teaching experience of mentoring for an undergraduate medicine class over the course of a six-year period (2014 to 2020).

Experience report: The mentoring actions were planned every six months in a meeting between mentor and mentees. The eligible themes were chosen through brainstorming to converge on the main collective demands. The topics included, for example: The patient's view of interaction with health students; The future of recently graduated doctors; Core skills of a doctor. The most frequently used tools were: Circle learning; Activities based on methodologies in small and large groups; Informal meetings with the whole class; Individual meetings; Formal and informal digital spaces. The actions were developed, over the six years, by the same teacher, which helped construct and consolidate the bond between mentor and mentees.
\end{abstract}

Discussion: Mentoring was configured as a powerful strategy, conducted with flexibility to permeate the needs of students, directing them towards the individual and collective development of professionalism. Among the secondary gains, the stimulation of teacher development stands out, a condition that required receptivity to interaction and recognition of the learners' experience.

Conclusion: This experience demonstrated that the essence of mentoring is related to the connection and the preparation of humans to deal with humans, regardless of the social role they are playing.

Keywords: Mentoring; Medicine; Teacher Development.

${ }^{1}$ Universidade Federal do Triângulo Mineiro, Uberaba, Minas Gerais, Brasil.

Editora: Patrícia Lacerda Bellodi

Recebido em 25/02/21; Aceito em 04/03/21.

Avaliado pelo processo de double blind review. 


\section{INTRODUÇÃO}

A compreensão do papel da mentoria no contexto de ensino-aprendizagem da graduação de estudantes de Medicina no Brasil tem sido consolidada ao longo do tempo.

Tradicionalmente, os cursos de Medicina eram pautados na interação educacional entre docentes e estudantes por meio de aulas expositivas e atividades práticas. A ampliação da utilização de metodologias ativas nas escolas médicas, tais como aprendizagem baseada em problemas, trouxe para esse cenário a qualificação de diferentes funções dos mesmos atores desse processo. Nesse contexto, Botti et al. ${ }^{1}$ contribuíram para o esclarecimento dos papéis atribuídos ao educador, como preceptor, supervisor, tutor e mentor. Essa referência, com base em revisão da literatura, direciona como principais características do mentor (p. 371): "Guiar, orientar e aconselhar na realização dos objetivos pessoais, buscando o desenvolvimento interpessoal, psicossocial, educacional e profissional"; local de atuação: "Fora do ambiente imediato de prática profissional", não devendo atuar como avaliador com atribuição de nota e tendo como principais requisitos: "Capacidade de se responsabilizar, de servir como guia, de oferecer suporte e de estimular o desenvolvimento do raciocínio crítico; Capacidade de ouvir, questionar e estimular justificações"1.

Em 2013, o colegiado do curso de Medicina da Universidade Federal do Triângulo Mineiro (UFTM) aprovou a criação do Programa de Mentoria para os estudantes de graduação. Foram escolhidos na ocasião docentes/preceptores nos quais se identificavam os principais requisitos listados como essenciais para serem considerados mentores, com base na literatura. Os convidados foram alocados nas 12 turmas vigentes (com cerca de 40 alunos cada), com a perspectiva de acompanhar esses estudantes até o término da graduação.

O presente artigo tem como objetivos relatar e discutir a experiência docente do exercício da mentoria para uma turma de graduação em Medicina durante o período de seis anos (de janeiro de 2014 a janeiro de 2020).

\section{RELATO DE EXPERIÊNCIA}

Ser convidado para compor o Programa de Mentoria do curso de Medicina da UFTM foi inicialmente considerado um reconhecimento pelos pares de qualificação diferenciada como educador. Esse convite não veio acompanhado de um manual de instruções, sendo as diretrizes gerais muito semelhantes à referência de Botti et al. ${ }^{1}$. Descrevo o caminho percorrido por vislumbrar a potencial utilidade na consolidação das estratégias de sucesso para o exercício da mentoria nas escolas médicas brasileiras.

O primeiro contato com a turma foi caracterizado por apresentar e envolver os estudantes nas premissas que dariam suporte às nossas ações da mentoria, as quais podem ser sintetizadas nos próximos dois textos, frequentemente revisitados ao longo dos seis anos:

Se fosse ensinar a uma criança a beleza da música não começaria com partituras, notas e pautas. Ouviríamos juntos as melodias mais gostosas e lhe contaria sobre os instrumentos que fazem a música. Aí, encantada com a beleza da música, ela mesma me pediria que lhe ensinasse o mistério daquelas bolinhas pretas escritas sobre cinco linhas. Porque as bolinhas pretas e as cinco linhas são apenas ferramentas para a produção da beleza musical. A experiência da beleza tem de vir antes ${ }^{2}$ (p. 103).

Filosofia Africana: "Umuntu ugumuntu nga bantu: Ser um ser humano é afirmar a própria humanidade reconhecendo a humanidade dos Outros, e com base nisso, estabelecer relacionamento humano com eles ${ }^{3}$ (p. 134).

A partir de então, semestralmente foram realizadas reuniões para o planejamento das atividades da mentoria. Essa periodicidade nos pareceu apropriada, e foi possível perceber o amadurecimento do grupo perante a realidade dinâmica que experimentava no curso. Em cada reunião de planejamento, partia-se de uma tempestade de ideias em que demandas individuais eram direcionadas para convergir nas principais demandas coletivas.

Mesmo com as ponderações de que o mentor deveria atuar "fora do ambiente imediato de prática profissional", em distintas ocasiões foram planejadas atividades por meio das quais os estudantes vivenciaram oportunidades educacionais direcionadas às lacunas do currículo formal do curso. A escuta ativa dos anseios dos estudantes, acompanhada da amplitude de possibilidades de ações educacionais que trouxessem significado para eles, tornou esse processo factível, com grande envolvimento afetivo dos discentes e sem choque ou ruído com o currículo formal.

Essa escolha de percurso se deveu a uma clara percepção de que não seria possível exercer plenamente a função de mentor de um grupo que não se interessasse verdadeiramente pelas ações propostas. Dessa forma, foi possível aliar os anseios dos estudantes às inserções direcionadas a reflexões mais amplas, atendendo à meta de aconselhá-los e guiálos no desenvolvimento profissional e pessoal. Partiu-se do pressuposto de que todos os temas eram "elegíveis", desde que a abordagem fosse direcionada ao atendimento do objetivo pretendido com o Programa de Mentoria.

Ao longo dos seis anos de acompanhamento, abordaram-se os seguintes temas: visão do paciente ante a interação com estudantes das profissões da saúde, identificação dos atores e espaços da rede de atenção à saúde, habilidades 
de atendimento em primeiros socorros, movimento estudantil, fundamentos de lógica, argumentação e falácias, currículo oculto, integração básico-clínico em medicina tropical, entrevista médica, habilidades de comunicação, postura médica no atendimento aos pacientes, futuro dos recémformados, matriz de competências essenciais para a formação do médico, entre outros.

As ferramentas utilizadas mais frequentemente foram: rodas de conversa com diversos formatos (convidando paciente, convidando alunos mais adiantados ou egressos, em pequenos grupos para conversas, direcionadas ou não, em temáticas específicas), atividades baseadas em metodologias ativas em pequenos e grandes grupos (o que motivou bastante os estudantes que têm o currículo baseado em aulas tradicionais), encontros informais com a turma toda (esses momentos foram especialmente importantes durante o internato, período no qual a divisão em grupos favoreceu o distanciamento entre os colegas, e era perceptível a celebração do encontro), encontros individuais (voltados ao aconselhamento na escolha de especialidades médicas e, ocasionalmente, demandas específicas) e espaços formais e informais de tecnologia (Moodle foi utilizado como apoio em diversas ações e WhatsApp como uma ferramenta de comunicação mais ágil).

A criação do Programa de Mentoria no curso de Medicina foi sucedida de uma discussão sobre a sua institucionalização. A partir de 2016, a participação no Programa de Mentoria da UFTM foi considerada uma opção para contabilizar como Atividades Acadêmico-Científico-Culturais (AACC), cuja carga horária necessita ser integralizada pelo estudante até o oitavo período do curso.

De forma geral, a média de participação dos estudantes nas atividades do Programa de Mentoria ao longo dos seis anos ficou em torno de $70 \%$ dos convidados. Não houve incremento de participação a partir de 2016 quando foram contabilizadas como AACC, e também não foi verificada redução na participação durante o internato. Todos os estudantes da turma participaram de pelo menos um semestre de atividades do Programa de Mentoria. Uma singularidade dessa turma foi ter sido a primeira na universidade com destinação de $50 \%$ das vagas para ingresso por meio das ações afirmativas. Foi perceptível que o espaço da mentoria funcionou como ponte para a inclusão dos diferentes olhares sobre a vida e a medicina, advindos da diversidade inerente ao grupo.

Durante o processo, o desenvolvimento docente do mentor foi um caminho percorrido de forma "solitária". Não foram concretizadas ações permanentes da universidade voltadas para direcionar os mentores no exercício da sua função. Tampouco houve convergência entre os docentes mentores para uma busca coletiva de percursos comuns. Na prática, os próprios estudantes mentorados foram os principais parceiros nessa busca de desenvolvimento docente, o que reforça a mão dupla do processo de ensino-aprendizagem.

Não se realizou uma avaliação formal dos egressos quanto ao Programa de Mentoria vivenciado. No entanto, foram recebidas diversas devolutivas de docentes, preceptores, outros estudantes e dos próprios mentorados sobre o sucesso desse formato de programa. Chamou a atenção a homenagem da turma ao convidar a docente mentora para emprestar o seu nome como identidade da turma (Nome da Turma), após um longo período no qual tais honrarias estavam direcionadas aos preceptores não docentes.

\section{DISCUSSÃO}

The practice of medicine is an art, not a trade; a calling, not a business; a calling in which your heart will be exercised equally with your head. Often the best part of your work will have nothing to do with potions and powders, but with the exercise of an influence of the strong upon the weak, of the righteous upon the wicked, of the wise upon the foolish (William Osler, 1914) 4 .

O médico William Osler, reconhecido como "pai da medicina moderna", foi enfático em seus escritos sobre a essência humana da profissão ${ }^{4}$. Aliar o ensino das competências técnicas à percepção do médico como um ser humano preparado para cuidar daquilo que é inerente à natureza humana torna-se um desafio para a educação médica. A mentoria se configura entre as potenciais estratégias capazes de agregar o conjunto de habilidades relacionadas ao profissionalismo, com flexibilidade para permear as necessidades dos educandos.

Os programas de mentoria apresentam-se com grande amplitude de atuação. Frei et al. $^{5}$ e Nimmons et al. ${ }^{6}$ são alguns dos autores que sintetizaram os diferentes objetivos da mentoria, os quais são mencionados a seguir:

- Mentoria clínica: voltada para preparar estudantes de Medicina dos últimos anos e qualificar os próximos médicos iniciantes nos serviços. Assim, médicos recém-qualificados poderiam atuar como mentores, facilitando o ensino de habilidades clínicas à beira do leito.

- Desenvolvimento pessoal de profissionalismo: os mentores são orientados a auxiliar e aconselhar os alunos, com a perspectiva de servir como "modelos" para os estudantes. Nesse sentido, médicos experientes podem ter uma bagagem mais ampla para o direcionamento dos aprendizes.

- Carreira acadêmica e pesquisa: objetivam cultivar uma atitude positiva em relação à carreira acadêmica e 
favorecer que os mentorados reconheçam a pesquisa como forma de beneficiar suas carreiras futuras.

- Inclusão de minorias: Ante a percepção da falta de diversidade social entre os estudantes da profissão médica, tem sido recomendado um sistema de mentoria voltado para atender às especificidades invisibilizadas desses grupos.

- Mentoria entre pares: situação em que os estudantes mais avançados auxiliam no desenvolvimento de habilidades dos iniciantes. Geralmente, voltada para o ensino de aspectos específicos do currículo, como uma habilidade clínica ou procedimental.

De alguma forma, em diferentes graus, nossa experiência perpassa todos os diversos objetivos relatados. Convém ressaltar a pluralidade de potenciais percursos para atingir tais objetivos; além disso, nem todos os objetivos serão adotados universalmente em todos os programas de mentoria. Assim, a interação entre mentor e mentorados parece ser um elementochave para o direcionamento dinâmico dos objetivos e das ações em cada contexto.

Existem recomendações de boas práticas para o exercício da mentoria, as quais necessitam de um esforço institucional para garantir o seu cumprimento. Considerando as especificidades de cada programa, são aspectos fundamentais reflexões relacionadas ao recrutamento de mentores e mentorados, à duração dessa interação e às possibilidades de modificação ao longo do processo ${ }^{6}$. Ramani et al. ${ }^{7}$ apresentaram 12 dicas úteis relacionadas às boas práticas, as quais poderiam ser resumidas assim: o mentor precisa: 1 . ter clareza das expectativas para o seu papel, ter boa habilidade de escuta e de feedback; 2 . ter consciência sobre as dificuldades relacionadas a culturas e gêneros diferentes (tolerância zero para discriminação); 3. dar suporte aos mentorados, mas desafiá-los também; 4. ter um fórum para expressar suas incertezas; 5 . ter consciência dos limites da sua atuação profissional; 6. também ser mentorado; 7. ser reconhecido; 8 . ser recompensado; 9. ter tempo protegido para o exercício da mentoria; 10 . ter suporte para encaminhamento de demandas dos mentorados; 11. incentivar o aprendizado entre pares; 12 . avaliar continuamente a efetividade do programa de mentoria (incluindo ser avaliado).

Outro aspecto relevante refere-se aos potenciais comportamentos dos indivíduos, relacionados às gerações a que pertencem, podendo influenciar no êxito da instituição das boas práticas de mentoria. Reconhecer as diferenças de resposta aos estímulos entre a geração dos mentores e a dos mentorados pode ser essencial para flexibilizar padrões, com vistas a alcançar efetividade das ações ${ }^{8}$.

A percepção dos efeitos positivos para os estudantes na experiência relatada neste artigo converge com os relatos descritos por Martins et al. ${ }^{9}$. Chama a atenção das autoras a aferição de um "mosaico de diferentes vivências", nas quais se puderam verificar contrastes entre fortalezas e fragilidades. Nosso relato de experiência tem a limitação de não ter realizado uma avaliação sistematizada da opinião dos mentorados. No entanto, questões apontadas pelas autoras como desafios, tais como "necessidade do estabelecimento de um claro propósito para a atividade" e "sensibilização dos próprios alunos", não foram marcantes na nossa experiência. Nessa direção, é possível refletir que a rigidez no seguimento de todas as diretrizes para a "mentoria ideal" pode distanciar o mentor das aspirações dos estudantes mentorados, os quais têm uma longa trajetória de práticas de "educação bancária". Ter sensibilidade para identificar o momento no qual, eventualmente, se deve abrir mão do cumprimento das recomendações ideais com vistas a envolver afetivamente os educandos pode trazer mais fluidez e naturalidade nesse processo.

Outro aspecto importante desta experiência foi - Programa de Mentoria mostrar-se como um "espaço protegido" para a expressão da diversidade. O reforço positivo de pertencimento ao grupo propiciou trocas profundas entre visões de mundo em construção. Durante o acompanhamento dessa turma, também foi desenvolvida uma pesquisa com a intenção de aferir potenciais diferenças de envolvimento acadêmico entre os estudantes com entrada por ampla concorrência e os por ação afirmativa. Não foi constatada nenhuma diferença nesse aspecto, mas chamou a atenção que os estudantes cujo ingresso se deu por ações afirmativas apresentaram significativamente mais propensão a "Compreender os determinantes sociais, culturais, econômicos, biológicos e políticos do processo saúde-doença e da função médica" (p. 133) desde os períodos iniciais do curso ${ }^{10}$.

Por fim, o desenvolvimento docente para o mentor sem dúvida é um aspecto fundamental para o sucesso do programa de mentoria. Deve ser continuado e assumido institucionalmente como condição essencial para a sua existência ${ }^{11}$. Essa premissa não exime o mentor de sua responsabilidade no seu próprio processo de qualificação. A promoção de ações formativas sempre será insuficiente se não houver uma decisão individual do mentor em assumir o seu próprio processo de qualificação. Nesse sentido, configuram-se como elementos facilitadores a postura de estar aberto ao constante feedback fornecido pelos mentorados e a receptividade aos conhecimentos e às habilidades que os estudantes já possuem quando chegam ao programa.

\section{CONCLUSÃO}

A mentoria para graduandos em Medicina é uma oportunidade de crescimento em diversas direções, tendo 
como beneficiados, além dos estudantes, os docentes, a instituição, os pacientes e o ambiente acadêmico. É fundamental compartilhar as experiências construídas nos cenários educacionais brasileiros. A frase do poeta espanhol Antonio Machado - "Caminhante, não há caminho, o caminho se faz ao caminhar" - faz muito sentido quando estamos falando de programas de mentoria. De qualquer modo, é desejável que tenhamos uma visão mais panorâmica das potenciais pedras e dos desvios desse caminho.

\section{CONFLITO DE INTERESSES}

Declaro não haver conflito de interesses neste estudo.

\section{FINANCIAMENTO}

Não houve financiamento para a realização desta pesquisa.

\section{REFERÊNCIAS}

1. Botti SHO, Rego S. Preceptor, supervisor, tutor e mentor: quais são seus papéis? Rev Bras Educ Med. 2008;32(3):363-73.

2. Alves R. Ostra feliz não faz pérola. São Paulo: Planeta; 2008 [acesso em 25 fev 2021]. Disponível em: http://alma.indika.cc/wp-content/ uploads/2015/04/Ostra-Feliz-Nao-Faz-Perola-Rubem-Alves.pdf.

3. Paula N, Wer C. Filosofia Africana: um estudo sobre a conexão entre ética e estética. Voluntas: Revista Internacional de Filosofia. 2019;10:128-38.

4. Silverman ME, Bryan CS, Murray TJ, editors. The Quotable Osler. Philadelphia: American College of Physicians; 2010.

5. Frei E, Stamm M, Fischer BB. Mentoring programs for medical students - a review of the PubMed literature 2000-2008. BMC Med Educ. 2010;10(32):114 [acesso em 25 fev 2021]. Disponível em: http://www.biomedcentral. com/1472-6920/10/32.

6. Nimmons D, Giny S, Rosenthal J. Medical student mentoring programs: current insights. Adv Med Educ Pract. 2019;10:113-23.

7. Ramani S, Gruppen L, Kachur EK. Twelve tips for developing effective mentors. Med Teach. 2006;28(5):404-8.

8. Waljee JF, Chopra V, Santi S. Mentoring Millennials. JAMA. 2020;323(17):1716-7.

9. Martins AF, Bellodi PL. Mentoring in medical students: a humane and developmental experience. Interface (Botucatu). 2016;20(58):715-26.

10. Teixeira LAS, Couto MO, Santos PVL. Ação afirmativa em uma escola médica no Brasil: perspectivas dos estudantes. Revista Triângulo. 2018;11(3):12938 [acesso em 25 fev 2021]. Disponível em: http://seer.uftm.edu.br/ revistaeletronica/index.php/revistatriangulo/article/viewFile/2670/3309.

11. Burgess A, van Diggele C, Mellis C. Mentorship in the health professions: a review. Clin Teach. 2018 June;15(3):197-202. 